\title{
Membranes for Carbon Dioxide Capture from Kuwait Power Stations: Process and Economic Analysis
}

\author{
Y. Alqaheem* \\ Petroleum Research Center, Kuwait Institute for Scientific Research, Kuwait \\ E-mail: yqaheem@kisr.edu.kw
}

Received 1 November 2021, Accepted 8 November 2021

\begin{abstract}
Power plants account for $42 \%$ of the total emitted carbon dioxide in Kuwait. To reduce global warming, it is necessary to capture carbon dioxide from the flue gas of power stations. In this paper, commercial polyethylene-oxide based membranes were simulated using a two-stage setup for the production of a stream containing 90 mol\% of carbon dioxide. The compression and the vacuum systems were evaluated in this study in terms of the membrane area, flow of the captured carbon dioxide, power consumption, and capital investment. Results show that the compression system requires less membrane area but it was not economical due to the high energy requirement of the compressor. In the vacuum system, the membrane area increased by a fold of 30 but the energy consumption was reduced by $96 \%$. It was concluded that the vacuum system reduced the capital cost by $63 \%$ in contrast with the compression system. Compared to other technologies such as amine scrubber and pressure swing adsorption, the vacuum membrane system can provide a very attractive solution for carbon dioxide separation with a capture cost of $30.1 \$$ per ton.
\end{abstract}

Keywords: Power station, Flue gas, Carbon dioxide capture, Gas-separation membranes, UniSim simulation.

\section{Introduction}

Global warming refers to the rise in the world's temperature due to human activities. The main activity is the combustion of fossil fuel which increases the content of carbon dioxide in the atmosphere [1]. Carbon dioxide and other greenhouse gases absorb solar radiations that have bounced off the earth's surface and this results in a climb in the climate temperature [2]. Consequently, the sea level will jump up, harvest productivity will shrink, and water quality will be affected [3]. Therefore, carbon dioxide capture is necessary to combat global warming and to reduce its impact.

In Kuwait, there are many sources of carbon dioxide such as power plants, transportations, refineries, and other industries. However, power plants account for nearly $42 \%$ of the total emitted carbon dioxide [4]. There are seven power stations in Kuwait that produce a total power of $15.5 \mathrm{GW}$ and generate 114,000 tons of carbon dioxide daily. The seven power stations are Shuwaikh (252 MW), Shuaiba south (720 MW), Shuaiba North (876 MW), Doha East (1,158 MW), Doha West (2,360 MW), Sabiya (4,867 MW), and Alzour $(5,306 \mathrm{MW})$. Alzour is considered as the largest power station in Kuwait and it produces 39,000 tons of carbon dioxide daily which is more than one-third of the generated carbon dioxide from all power stations.

Conventionally, the amine unit is used to separate carbon dioxide from flue gas. The unit is based on chemical absorption in which the gas passes through sprays of aminebased solvent. Carbon dioxide will react and dissolve in the solvent. The concentrated solvent is then regenerated by heating the solution and then it will be recycled back to the unit. Despite the high removal efficiency of the amine unit, the process suffers from some issues related to solvent flooding and disposal.
The membranes provide another path for carbon dioxide separation without the need for solvents nor regeneration step. The technology is also compact and easy to be integrated within the process. The transport mechanism in polymeric membranes is based on the solution-diffusion model in which carbon dioxide dissolves and diffuses through the membrane and this produces a retentate (residue) stream with less carbon dioxide content [5]. The membranes are also capable of producing a high-quality carbon dioxide stream [6-8]. This concentrated stream has many applications. For instance, it can be injected into wells to enhance oil recovery [9]. Moreover, the stream can be used for the production of fire extinguishers, dry ice, and soft drinks. Furthermore, it can be utilized as a feedstock for various industries such as plastics and methanol [10].

In this work, the removal of carbon dioxide from the flue gas of Kuwait power stations was simulated in UniSim using a tailor-made membrane unit. Polyethylene-oxide-based polymers were considered in this study because they are known to have excellent performance among other commercial membranes in terms of carbon dioxide permeation and carbon dioxide-to-nitrogen selectivity [11]. The membranes are commercialized and developed by Membrane Technology and Research (MTR) [12]. The membrane's performance was evaluated based on the calculated carbon dioxide recovery in the product gas and the required membrane's area for producing a stream containing $90 \mathrm{~mol} \%$. It is stated that this concentration can be stored underground or used for enhanced oil recovery [13]. An economic analysis was carried out as well by calculating the capital and operating costs of the membrane system. Two different designs were discussed in this study, the compression and the vacuum systems. The two processes were compared in terms of the membrane area, flowrate of 
the captured carbon dioxide, energy consumption and the capital/operating cost of the system. The main objective of this research to investigate the feasibility of using the membrane system to capture carbon dioxide from Kuwait power stations. The membrane system will be compared with other separation technologies such as amine scrubber and pressure swing adsorption (PSA) in terms of the capture cost (\$ per ton).

\section{Methodology}

The flue gas composition of the power station depends on the used fuel for combustion [14]. For example, it is known that coal gives a higher concentration of carbon dioxide in the flue gas while natural gas produces the minimum carbon dioxide. Petroleum fractions such as fuel oil give carbon dioxide emissions between coal and natural gas. It is reported that $85 \%$ of Kuwait power stations use fuel oil [15]. Therefore, the flue gas was modeled accordingly and the data is given in Table 1. The flue gas is assumed to have $10 \mathrm{~mol} \%$ of carbon dioxide along with water $(10 \mathrm{~mol} \%)$, oxygen (6 mol\%), and balance nitrogen. The flue gas flowrate of each station is shown in Table 2.

Polyethylene-oxide based material was selected with a spiral-wound geometry. Unfortunately, UniSim lacks a membrane module so the unit was modeled using a component-splitter with an integrated spreadsheet [16]. Mole balance across the membrane can be applied by the following equation (neglecting accumulation):

$$
x_{F} n_{F}=y_{P} n_{P}+x_{R} n_{R}
$$

where $n$ is the number of moles $(\mathrm{kmol}), x_{F}$ is the mole fraction of component $i$ in the feed, $x_{R}$ is the mole fraction in the retentate (reject), and $y_{P}$ is the mole fraction in the permeate. Equation 1 can be rewritten as:

$$
y_{P} n_{P}=x_{F} n_{F}-x_{R} n_{R}=Q A\left(\overline{x P_{F}-y P_{P}}\right)
$$

where $Q$ is the permeance in $\mathrm{kmol} /\left(\mathrm{m}^{2} \mathrm{~h} \mathrm{kPa}\right)$. Gas permeation unit (GPU) is another unit of permeance which equals to $3.35 \times 10^{-10} \mathrm{~mol}\left(\mathrm{~m}^{2} \mathrm{~s} \mathrm{~Pa}\right) . A$ is the membrane area $\left(\mathrm{m}^{2}\right)$, and the third term is the trans-membrane pressure difference $(\mathrm{kPa}) . P_{F}$ is the feed pressure while $P_{P}$ is the permeate pressure. The trans-membrane pressure difference can be estimated by:

$$
\left(\overline{x P_{F}-y P_{P}}\right) \cong\left[\frac{x_{F}-x_{R}}{\ln \left(\frac{x_{F}}{x_{R}}\right)}\right] P_{F}-y_{P} P_{P}
$$

For quick calculations and better convergence, the previous equation is approximated by [17]:

$$
\frac{x_{F}-x_{R}}{\ln \left(\frac{x_{F}}{x_{R}}\right)} \cong\left[x_{F} x_{R}\left(\frac{x_{F}+x_{R}}{2}\right)\right]^{1 / 3}
$$

The simulation was run by first guessing the stage-cut $(\theta)$ of the components in the permeate using:

$$
\theta_{\text {Guess }}=\frac{y_{P} n_{P}}{x_{F} n_{F}}
$$

After that, $x_{R}$ and $y_{P}$ are solved simultaneously using the following equations:

$$
\begin{aligned}
& y_{P} n_{P}=x_{F} n_{F}-x_{R} n_{R} \\
& \sum_{i=1}^{n} x_{F}=1 ; \sum_{i=1}^{n} x_{R}=1 ; \sum_{i=1}^{n} y_{P}=1
\end{aligned}
$$

Hereafter, the calculated $x_{R}$ and $y_{P}$ are used to calculate the stage-cut using the permeance data:

$$
\theta_{\text {Calc }}=\frac{Q A\left(\overline{x P_{F}-y P_{P}}\right)}{x_{F} n_{F}}
$$

The guessed stage-cut is then changed until the calculated $y_{P}$ gives the same value as the guessed with an error no more than 0.001 . The membranes process was modeled using a two-stage setup for a better overall performance as given in Figure 1. The flue gas was assumed to be at atmospheric pressure and a compressor was used to increase the gas pressure to 5 bar. Due to Joule-Thomson effect, the gas temperature increased and coolers were added to set the temperature to $25^{\circ} \mathrm{C}$. The permeate of the first membrane was fed to another compressor to increase the pressure back to 5 bar and it was recycled and mixed with the feed. For vacuum operation, the feed pressure to the membrane was set to 1 bar while the permeate pressure was reduced to 0.2 bar using a vacuum pump. The operating conditions used in this study are given in Table 3. The permeance and selectivity data were taken from commercial polyethyleneoxide based membranes reported in the literature are given in Table 4. In this simulation, the system is assumed to be completely mixed with no mass-transfer resistance across the membrane.

Table 1. Composition of the flue gas of Kuwait power stations.

\begin{tabular}{ll}
\hline Component & Mole Fraction $(\%)$ \\
\hline Carbon dioxide $\left(\mathrm{CO}_{2}\right)$ & 10 \\
Water $\left(\mathrm{H}_{2} \mathrm{O}\right)$ & 9 \\
Oxygen $\left(\mathrm{O}_{2}\right)$ & 6 \\
Nitrogen $\left(\mathrm{N}_{2}\right)$ & 75 \\
\hline
\end{tabular}

Table 2. Flue gas flowrate of Kuwait power stations and $\mathrm{CO}_{2}$ emissions.

\begin{tabular}{llll}
\hline Power Station & $\begin{array}{l}\text { Power Output } \\
(\mathrm{MW})\end{array}$ & $\begin{array}{l}\text { Flue Gas } \\
(\mathrm{kg} / \mathrm{s})\end{array}$ & $\begin{array}{l}\mathrm{CO}_{2} \text { Emissions } \\
(\mathrm{t} / \mathrm{d})\end{array}$ \\
\hline Shuwaikh & 252 & 143 & 1,848 \\
Shuaiba South & 720 & 408 & 5,281 \\
Shuaiba North & 876 & 497 & 6,425 \\
Doha East & 1,158 & 659 & 8,493 \\
Doha West & 2,360 & 1,333 & 17,310 \\
Sabiya & 4,867 & 2,767 & 35,698 \\
Alzour & 5,306 & 3,000 & 38,917 \\
\hline
\end{tabular}

Table 3. Operating conditions used in the simulation study.

\begin{tabular}{lll}
\hline Property & $\begin{array}{l}\text { Compression } \\
\text { Operation }\end{array}$ & $\begin{array}{l}\text { Vacuum } \\
\text { Operation }\end{array}$ \\
\hline Flue gas Pressure & $1 \mathrm{bar}$ & $1 \mathrm{bar}$ \\
Feed pressure to membranes & $5 \mathrm{bar}$ & $1 \mathrm{bar}$ \\
Feed temperature to membranes & $25^{\circ} \mathrm{C}$ & $25^{\circ} \mathrm{C}$ \\
Retentate Pressure & $5 \mathrm{bar}$ & $1 \mathrm{bar}$ \\
Retentate Temperature & $25^{\circ} \mathrm{C}$ & $25^{\circ} \mathrm{C}$ \\
Permeate Pressure & $1 \mathrm{bar}$ & $0.2 \mathrm{bar}$ \\
\hline
\end{tabular}




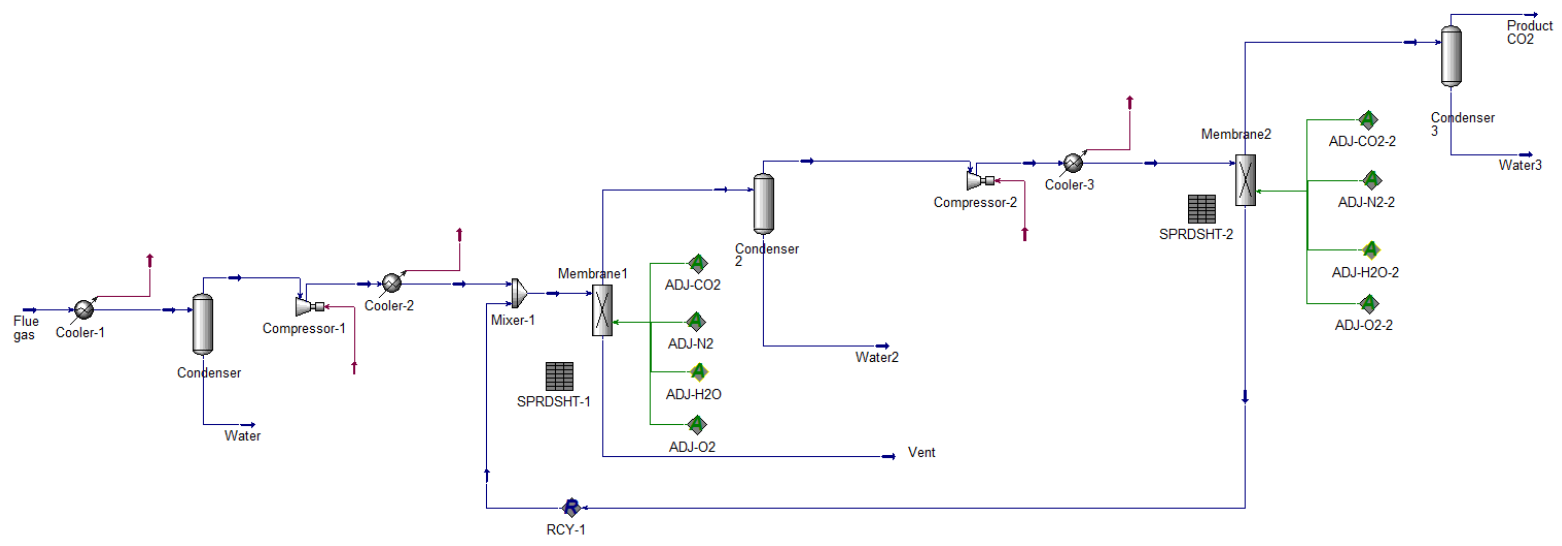

Figure 1. Process flow diagram of the simulated two-stage membrane for $\mathrm{CO}_{2}$ recovery from Kuwait power stations using compression system.

Table 4. Permeance and selectivity data of commercial polyethylene-oxide based membranes [12, 18].

\begin{tabular}{lll}
\hline Component & $\begin{array}{l}\text { Permeance } \\
\mathrm{kmol} /\left(\mathrm{m}^{2} \mathrm{~h} \mathrm{kPa}\right)\end{array}$ & Selectivity to $\mathrm{CO}_{2}$ \\
\hline Carbon dioxide $\left(\mathrm{CO}_{2}\right)$ & $1.09 \times 10^{-3}$ & - \\
Water $\left(\mathrm{H}_{2} \mathrm{O}\right)$ & 0.72 & - \\
Nitrogen $\left(\mathrm{N}_{2}\right)$ & $2.17 \times 10^{-5}$ & 50 \\
Oxygen $\left(\mathrm{O}_{2}\right)$ & $3.62 \times 10^{-5}$ & 30 \\
\hline
\end{tabular}

The permeance data is assumed to be independent of the feed composition and ambient temperature. The developed membrane module was tested with reported data [19] and the error was within $\pm 10 \%$.

\section{Results and Discussion \\ 3.1 Compression Operation}

UniSim was used to calculate the required membrane area and the mass flowrate of the captured carbon dioxide using a two-stage membrane system. The product purity was maintained at $90 \mathrm{~mol} \%$ carbon dioxide for all the stations. In the compression design, the feed pressure to the membrane was at 5 bar while the permeate was at atmospheric pressure. The results are given in Table 5 and it is clear that the membrane area (total area of the two units) is proportional to the power station output. For instance, for Shuwaik power station (252 MW), the membrane area is $1,864 \mathrm{~m}^{2}$ while for Alzour station $(5,306 \mathrm{MW})$, the needed area is $45,316 \mathrm{~m}^{2}$. The flow of captured carbon dioxide (ton per day) also increases with the power station output. For example, in Shuwaikh power station, the membrane system can capture 47 tons per day of carbon dioxide while for Alzour power station, 996 tons per day of carbon dioxide is recovered.

To study the feasibility of the compression membrane system, an economic assessment was performed [19]. The capital investment was calculated based on the cost of the membrane skid and the compressor. The membrane skid was priced at $50 \$$ per $\mathrm{m}^{2}$ and the compressor cost was $500 \$$ per $\mathrm{kW}$ [19]. The installation cost was assumed to be $60 \%$ of the capital investment. The annual operating cost was defined as the sum of the utility bill and the maintenance charge. The utility bill was determined from the energy consumption of the compressor using Kuwait electricity tariff of $0.0075 \$$ per $\mathrm{kW}$.

The maintenance fee was assumed to be $5 \%$ of the capital cost. Table 6 shows the calculation steps for performing the economic assessment. Capital and operating costs for producing a $90 \mathrm{~mol} \%$ carbon dioxide stream from the flue
Table 5. Production of 90 mol\% $\mathrm{CO}_{2}$ stream from the flue gas of Kuwait power stations using a two-stage membrane system (compression operation).

\begin{tabular}{lllll}
\hline $\begin{array}{l}\text { Power } \\
\text { Station }\end{array}$ & $\begin{array}{l}\text { Power } \\
\text { Output } \\
(\mathrm{MW})\end{array}$ & $\begin{array}{l}\text { Flue Gas } \\
(\mathrm{kg} / \mathrm{s})\end{array}$ & $\begin{array}{l}\text { Captured } \\
\mathrm{CO}_{2}(\mathrm{t} / \mathrm{d})\end{array}$ & $\begin{array}{l}\text { Membranes } \\
\text { Area }\left(\mathrm{m}^{2}\right)\end{array}$ \\
\hline $\begin{array}{l}\text { Shuwaikh } \\
\text { Shuaiba }\end{array}$ & 252 & 143 & 47 & 1,864 \\
$\begin{array}{l}\text { South } \\
\text { Shuaiba }\end{array}$ & 720 & 408 & 198 & 8,180 \\
North & 876 & 497 & 224 & 8,756 \\
Doha East & 1,158 & 659 & 255 & 10,592 \\
Doha West & 2,360 & 1,333 & 613 & 22,978 \\
Sabiya & 4,867 & 2,767 & 869 & 37,348 \\
Alzour & 5,306 & 3,000 & 996 & 45,316 \\
\hline
\end{tabular}

gas of Kuwait power stations are given in Figure 2. It is obvious that the capital and operating costs significantly increase with the power station output. For example, the capital cost of recovering carbon dioxide from Shuwaikh power station is 24.5 million \$ while for Alzhour station, the cost is 516.9 million \$.

To calculate the cost of carbon dioxide capture, the following equation was used [17]:

$$
\begin{aligned}
& \text { Capture Cost (\$/ton) } \\
& =\frac{(P \times T \times E)+(0.2 \times \text { Capital Cost })}{F_{\mathrm{CO}_{2}} \times T}
\end{aligned}
$$

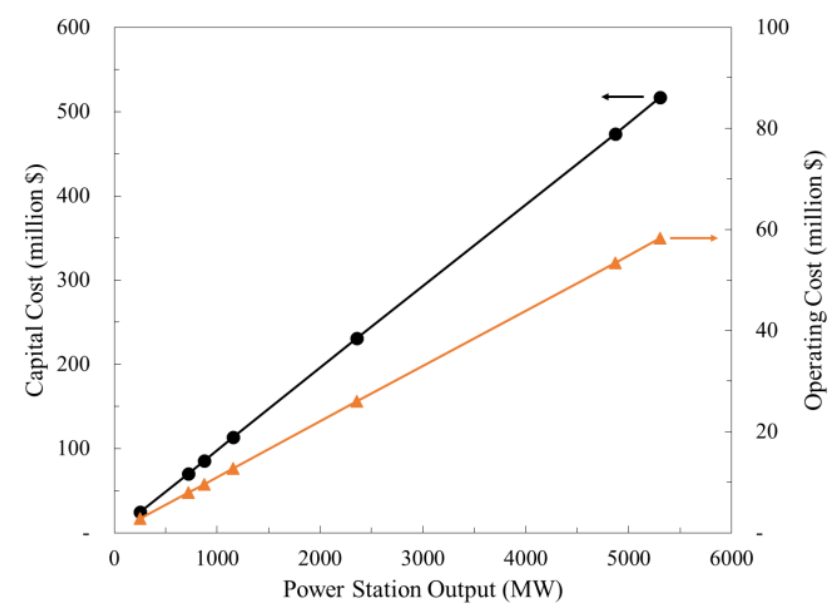

Figure 2. Power station output and the required capital and operating costs of the membrane system (two-stages) for production of $\mathrm{CO}_{2}(90 \mathrm{~mol} \%)$ using compression operation. 
Table 6. Parameters for the calculation of capital and operating costs of the membranes system [19].

\begin{tabular}{ll}
\hline Parameter & Value \\
\hline \multicolumn{2}{c}{ Capital Cost $^{(\mathrm{a})}$} \\
\hline Membrane skid (MS) & $50 \$$ per m ${ }^{2}$ \\
Compressor (C) & $500 \$$ per kW \\
Total Capital Cost (with installation cost) & $(\mathrm{MS}+\mathrm{C}) \times 1.6$ \\
Retentate Pressure & 5 bar \\
\hline \multicolumn{3}{l}{ Annual Operating Cost ${ }^{(\mathrm{b})}$} \\
\hline Maintenance (MT) & $0.0075 \$$ per kWh \\
Total Operating Cost & $5 \%$ capital cost \\
\hline
\end{tabular}

(a) Coolers' cost is not included. (b) labor cost and membrane replacement costs are not covered.

where $P$ is the input power $(\mathrm{kW})$ to the compressors, $T$ is the operation time (h per year), $E$ is the cost of the electricity ( $\$$ per $\mathrm{kW}$ ), and $\mathrm{F}_{\mathrm{CO}_{2}}$ is the mass flowrate of captured carbon dioxide (ton per $\mathrm{h}$ ). The plant is assumed to be operated on $85 \%$ capacity which gives $7,446 \mathrm{~h}$ per year. Based on the previous equation, the carbon dioxide capture cost of the membrane system (compression design) is $459.2 \$$ per ton. This cost is excessively high compared to other options for carbon dioxide separation such as the pressure swing adsorption (PSA) and amine process that cost 40 to $100 \$$ per ton of carbon dioxide [19, 20].

\subsection{Vacuum Operation}

From the previous section, it was concluded that the membrane system based on the compression process was uneconomical due to the high energy consumption of the compressors. In this section, vacuum pumps were used instead in which the feed pressure was decreased from 1 to

0.2 bar in the permeate. Because the pressure difference across the membrane was changed, it is expected that the membrane area and the flowrate of the captured carbon dioxide will change as well. Consequently, the simulation was used again to calculate these variables in addition to the power consumption. It should be noted that the product purity was still maintained at $90 \mathrm{~mol} \%$ carbon dioxide. Results are given in Table 7 and the use of the vacuum system considerably increased the amounts of captured carbon dioxide by $500 \%$. This is related to the membrane area that increased massively by 30 folds. Table 8 shows the energy reduction in using the vacuum system compared to the compression. Interestingly, the energy in the vacuum system was minimized by $96 \%$. It should be noted that for the compression design, all the feed gas has to be compressed while for the vacuum system, only the permeated gas has to be vacuumed and this explains the energy reduction. In addition, the vacuum pumps requires less energy to operate unlike the compressors [21]. So, for Shuwaikh power station, the energy input for compression is $30,442 \mathrm{~kW}$ while for the vacuum system, it is $978 \mathrm{~kW}$. In the vacuum design, about $10 \%$ of the gas is permeated through the membrane and this flow will be only vacuumed. So, if all the feed flow was vacuumed, roughly we need $9,780 \mathrm{~kW}$ and the energy comparison between compression and vacuum is about 3 times (as stated by Merkel et al. [19]), therefore the energy for the compression is $29,340 \mathrm{~kW}$ which is very close to the simulation data of $30,442 \mathrm{~kW}$.

Based on the above results, the use of the vacuum system greatly reduced the power consumption but the membrane area was notably increased. It is known that the price of the vacuum pump is four times the cost of the compressor which gives 2,000\$ per kW [22]. Economic analysis was carried out and the data is given in Figure 3. It is obvious that the capital and the operating costs of the vacuum system are lower compared to the compression system (reduction by 63\%). For example for Shuwaikh power station, the capital cost was cut from 24.5 million $\$$ to 7.1 million $\$$. The average capital expenditure is $27,768 \$$ per ton $\mathrm{CO}_{2}$ (per day) while the operation cost is $1,613 \$$. Using equation 11 , the cost of carbon dioxide capture is $20.1 \$$ per ton using the vacuum system. However, this expense does not include the cost for carbon dioxide liquefaction and transportation. These processes will cost around $10 \$$ per ton of carbon dioxide [19, $23]$. This gives a total capture cost of $30.1 \$$ per ton of carbon dioxide which is very attractive compared to other technologies such as PSA and amine scrubber that cost 40 to $100 \$$ per ton of carbon dioxide.

Furthermore, the membranes are known to be compact and occupy less space. For example, the membrane system can have one-third of the deck area of the amine scrubber [24]. This is advantageous especially for stations with a limited space like Shuwaikh power station. The station is located in a port and most of the surrounding area is occupied. The common industrial membrane skid has an area of $2,500 \mathrm{~m}^{2}$ with a length of $8.2 \mathrm{~m}$ and a diameter of $1.7 \mathrm{~m}$ [25]. Based on Table 7, the required membranes area is $50,000 \mathrm{~m}^{2}$ for Shuwaikh power plant and therefore, 20 skids are needed. It is estimated that the membrane module will have a length of $9.5 \mathrm{~m}$ with a width of $13.4 \mathrm{~m}$ as shown in Figure 4.

Table 7. Comparison between vacuum and compression operation for the capture of $\mathrm{CO}_{2}$ (tons per day) from flue gas of Kuwait power stations.

\begin{tabular}{lllll}
\hline Power & \multicolumn{2}{l}{ Vacuum Operation } & \multicolumn{2}{c}{ Compression Operation } \\
\cline { 2 - 5 } & $\begin{array}{l}\text { Captured } \\
\mathrm{CO}_{2}(\mathrm{t} / \mathrm{d})\end{array}$ & $\begin{array}{l}\text { Membranes } \\
\mathrm{Area}\left(\mathrm{m}^{2}\right)\end{array}$ & $\begin{array}{l}\text { Captured } \\
\mathrm{CO}_{2}(\mathrm{t} / \mathrm{d})\end{array}$ & $\begin{array}{l}\text { Membranes } \\
\mathrm{Area}\left(\mathrm{m}^{2}\right)\end{array}$ \\
\hline $\begin{array}{l}\text { Shuwaikh } \\
\text { Shuaiba }\end{array}$ & 238 & 50,026 & 47 & 1,864 \\
$\begin{array}{l}\text { South } \\
\text { Shuaiba }\end{array}$ & 1,174 & 199,720 & 198 & 8,180 \\
North & & 246,250 & 224 & 8,756 \\
Doha East & 1,545 & 324,544 & 255 & 10,592 \\
Doha West & 3,233 & 698,170 & 613 & 22,978 \\
Sabiya & 6,534 & $1,375,000$ & 869 & 37,348 \\
Alzour & 7,181 & $1,500,000$ & 996 & 45,316 \\
\hline
\end{tabular}

Table 8. Energy consumption for vacuum and compression operations for the generation of $90 \mathrm{~mol} \% \mathrm{CO}_{2}$ stream from power stations' flue gas using membranes.

\begin{tabular}{lllll}
\hline $\begin{array}{l}\text { Power } \\
\text { Station }\end{array}$ & $\begin{array}{l}\text { Power } \\
\text { Output } \\
(\mathrm{MW})\end{array}$ & $\begin{array}{l}\text { Flue Gas } \\
(\mathrm{kg} / \mathrm{s})\end{array}$ & $\begin{array}{l}\text { Vacuum } \\
\text { Operation } \\
(\mathrm{kW})\end{array}$ & $\begin{array}{l}\text { Compression } \\
\text { Operation } \\
(\mathrm{kW})\end{array}$ \\
\hline $\begin{array}{l}\text { Shuwaikh } \\
\text { Shuaiba }\end{array}$ & 252 & 143 & 978 & 30,442 \\
South & 720 & 408 & 3,597 & 86,944 \\
Shuaiba & 876 & 497 & 4,371 & 105,693 \\
North & & & & \\
Doha East & 1,158 & 659 & 3,834 & 140,393 \\
Doha West & 2,360 & 1,333 & 8,019 & 285,990 \\
Sabiya & 4,867 & 2,767 & 24,325 & 588,303 \\
Alzour & 5,306 & 3,000 & 26,728 & 641,696 \\
\hline
\end{tabular}




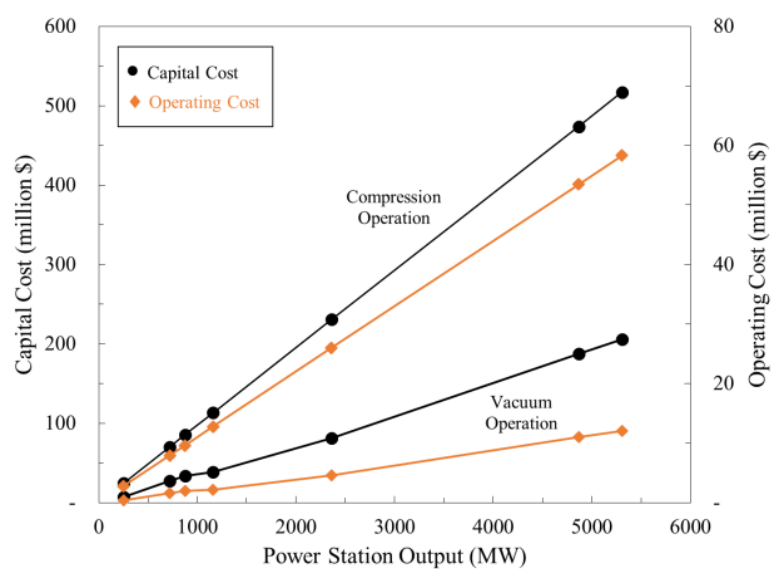

Figure 3. Economic comparison between vacuum and compression operations of a two-stage membrane system for producing $90 \mathrm{~mol}_{\%} \mathrm{CO}_{2}$.
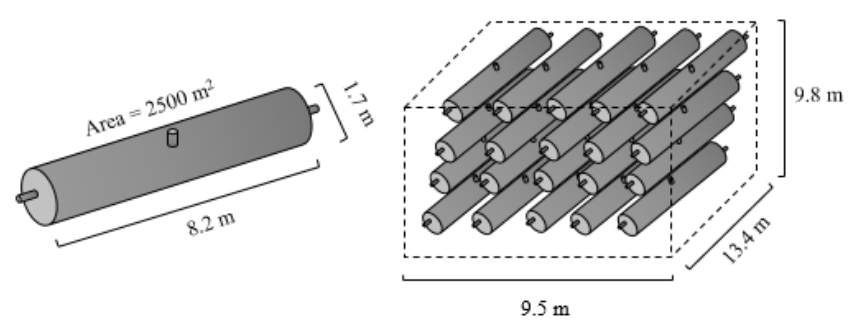

Figure 4. Estimated size of the membrane module for carbon dioxide capture in Shwwaikh power station.

\section{Conclusions}

Power stations are considered as the main source of carbon dioxide emissions in Kuwait. The sector generates 114,000 tons of carbon dioxide daily. Thus, carbon dioxide capture is obligatory to reduce the greenhouse effect. The membrane process is known to provide an environmentally friendly solution for gas separation. In this paper, commercial polyethylene-oxide based membranes were assessed for the production of a stream containing $90 \mathrm{~mol} \%$ from the flue gas of Kuwait power stations. The stream can be then utilized for enhanced oil recovery or other applications. The process was simulated in UniSim with the development of a customized membrane unit. Energy consumption, the flowrate of captured carbon dioxide, and the required membrane area were determined using the compression and vacuum systems. For the compression system, results show that the cost of carbon dioxide capture is $459.2 \$$ which is uneconomical compared to other technologies such as the amine scrubber and PSA which cost 40 to $100 \$$ per ton. On the other hand, the use of the vacuum system improved the rate of captured carbon dioxide six times but the membrane area was increased by 30 . Nevertheless, the economical assessment indicated that the vacuum system is still a cost-effective option due to the lower energy consumption. The price of carbon dioxide capture is $30.1 \$$ per ton which is very attractive to the industry. Therefore, this research recommends the use of the membrane vacuum system for the capture of carbon dioxide from Kuwait power stations. Furthermore, the membrane system is compact and can be installed even in busy locations such as Shuwaikh power station. However, in this study, the permeance data is assumed to be independent of feed composition and surrounding temperature. More experiments will be required to improve the accuracy of the model and this will be considered in future studies.
Abbreviations
$G P U$
Gas Permeation Unit
PSA
Pressure swing adsorption
MTR
Membrane Technology and Research

\section{Nomenclature}

$\theta$

A

$n$

$P$

$Q$

$x$

$y$

Stage cut

Membrane area $\left(\mathrm{m}^{2}\right)$

Molar flowrate $(\mathrm{kmol} / \mathrm{h})$

Pressure (bar)

Permeance $\left(\mathrm{kmol} /\left[\mathrm{m}^{2} \mathrm{~h} \mathrm{kPa}\right]\right)$

Mole fraction

Mole fraction in the product

Subscripts

$\begin{array}{ll}x_{F} & \text { Feed mole fraction } \\ x_{R} & \text { Reject mole fraction } \\ P_{F} & \text { Feed pressure } \\ P_{P} & \text { Permeate pressure } \\ y_{P} & \text { Product mole fraction }\end{array}$

\section{References:}

[1] T. Volk, CO2 rising: the world's greatest environmental challenge: MIT Press, 2010.

[2] E. Labrecque, Climate change: Cherry Lake Publishing, 2017.

[3] J. Belbute and A. Pereira, "Reference forecasts for $\mathrm{CO}_{2}$ emissions from fossil-fuel combustion and cement production in Portugal," Energy Policy, vol. 144, p. 111642 .

[4] A. Al-Mutairi, A. Smallbone, S. Al-Salem, and A. Roskilly, "The first carbon atlas of the state of Kuwait," Energy, vol. 133, pp. 317-326.

[5] J. Wijmans and R. Baker, "The solution-diffusion model: a review," J. Membr. Sci., vol. 107, pp. 1-21, 1995.

[6] M. Jaschik, M. Tanczyk, J. Jaschik, and A. J.-C., "The performance of a hybrid VSA-membrane process for the capture of $\mathrm{CO}_{2}$ from flue gas," Int.J. Greenhouse Gas Control, vol. 97, pp. 103037, 2020.

[7] A. Hussain and M.-B. Hägg, "A feasibility study of $\mathrm{CO}_{2}$ capture from flue gas by a facilitated transport membrane," J. Membr. Sci, vol. 359, pp. 140-148, 2010.

[8] R. Khalilpour, K. Mumford, H. Zhai, A. Abbas, G. Stevens, and E. Rubin, "Membrane-based carbon capture from flue gas: a review," J. Cleaner Prod., vol. 103, pp. 286-300, 2015.

[9] Z. Song, Y. Song, Y. Li, B. Bai, K. Song, and J. Hou, "A critical review of $\mathrm{CO}_{2}$ enhanced oil recovery in tight oil reservoirs of North America and China," Fuel, vol. 276, pp. 118006, 2020.

[10] D. Simakov, Renewable synthetic fuels and chemicals from carbon dioxide: fundamentals, catalysis, design considerations and technological challenges: Springer International Publishing, 2017.

[11] D. Sanders, Z. Smith, R. Guo, L. Robeson, J. McGrath, D. Paul, B. Freeman, "Energy-efficient polymeric gas separation membranes for a sustainable future: A review," Polymer, vol. 54, pp. 4729-4761, 2013.

[12] T. Brinkmann, J. Lillepärg, H. Notzke, J. Pohlmann, S. Shishatskiy, J. Wind, T. Wolff, "Development of $\mathrm{CO}_{2}$ selective poly(ethylene oxide)-based membranes: from 
laboratory to pilot plant scale," Engineering, vol. 3, pp. 485-493, 2017.

[13] M. Perera, R. Gamage, T. Rathnaweera, A Ranathunga, A. Koay, and X. Choi, "A review of $\mathrm{CO}_{2^{-}}$ enhanced oil recovery with a simulated sensitivity analysis," Energies, vol. 9, pp. 481, 2016.

[14] J.-M. Amann and C. Bouallou, " $\mathrm{CO}_{2}$ capture from power stations running with natural gas (NGCC) and pulverized coal (PC): Assessment of a new chemical solvent based on aqueous solutions of $\mathrm{N}$ methyldiethanolamine + triethylene tetramine," Energy Procedia, vol. 1, pp. 909-916, 2009.

[15] M. Savsar, M. Alardhi, and A. Almazrouee, "Capacity and availability analysis of power plants in Kuwait," in Process International Conference on Industrial Engineering and Operations Management, Istanbul, Turkey, 2012, pp. 1598-1607.

[16] R. Davis, "Simple gas permeation and pervaporation membrane unit operation models for process simulators," Chem. Eng. Technol, vol. 25, pp. 717-722, 2002.

[17] J. Chen, "Comments on improvements on a replacement for the logarithmic mean," Chem. Eng. Sci., vol. 42, pp. 2488-2489, 1987.

[18] "Post-combustion membranes for carbon capture," United Stated Depart of Energy, National Energy Technology Laboratory, 2013.

[19] T. Merkel, H. Lin, X. Wei, and R. Baker, "Power plant post-combustion carbon dioxide capture: an opportunity for membranes," J. Membr. Sci, vol. 359, pp. 126-139, 2010.

[20] S. Subraveti, S. Roussanaly, R. Anantharaman, L. Riboldi, and A. Rajendran, "Techno-economic assessment of optimised vacuum swing adsorption for post-combustion $\mathrm{CO}_{2}$ capture from steam-methane reformer flue gas," Sep. Purif. Technol., vol. 256, pp. 117832, 2021.

[21] R. Chavez and J. de J. Guadarrama, Recent technologies in capture of $\mathrm{CO}_{2}$ : Bentham Science Publishers, 2014.

[22] L. Zhao, E. Riensche, L. Blum, and D. Stolten, "How gas separation membrane competes with chemical absorption in postcombustion capture," Energy Procedia, vol. 4, pp. 629-636, 2011.

[23] L. Øi, N. Eldrup, U. Adhikari, M. Bentsen, J. Badalge, and S. Yang, "Simulation and cost comparison of $\mathrm{CO}_{2}$ liquefaction," Energy Procedia, vol. 86, pp. 500-510, 2016.

[24] A. Kohl and R. Nielsen, Gas purification: Elsevier Science, 1997.

[25] T. Merkel, "Development of membrane technology for $\mathrm{CO}_{2}$ capture at MTR," presented at the Symposium for Innovative $\mathrm{CO}_{2}$ Membrane Separation Technology, Tokyo, Japan, 2012. 